\title{
De eerste reeks callosotomieën
}

In 1939 werd voor het eerst systematisch geprobeerd het ontstaan van een gegeneraliseerde aanval te voorkomen door het corpus callosum door te snijden. In deze bijdrage worden de klinische observaties beschreven die hebben geleid tot callosotomie als ingreep om verspreiding van epileptische activiteit tegen te gaan. Er worden hierbij ook enkele kanttekeningen geplaatst.

Sinds mensenheugenis is trepanatie (het boren van gaten in schedels) toegepast, ook als behandeling voor epilepsie (Schijns et al., 20I5). Het idee was dat kwade geesten zo konden ontsnappen. Het kan ook zijn dat men gemerkt heeft dat bloed op de hersenen, waardoor epileptische prikkeling werd veroorzaakt, zo kon worden verwijderd. Toen onder meer door het werk van de Engelse neuroloog John Hughlings Jackson (I835-I9II) duidelijk werd dat de oorzaak van epilepsie in de cortex lag, ging men nadenken over chirurgisch ingrijpen op die plek waar het epileptisch focus zou liggen. De eerste pogingen om via corticale extirpatie (corticectomie) epilepsie te behandelen staan op naam van William Macewen (I848-I924), Victor Horsley (I857-I9I6) en Fedor Krause (I857-I937). Naast relatief kleine delen werden ook grotere delen, tot zelfs een hemisfeer (hemisferectomie) van aangetast hersenweefsel verwijderd in de hoop zo het ontstaan en de verspreiding van aanvallen te kunnen tegengaan.

\section{Callosotomie}

De grote verbindingsweg tussen beide hersenhemisferen is het corpus callosum, de hersenbalk. Callosotomie is een ingreep waarbij het corpus callosum (cc) wordt doorgesneden. De gedachte achter de callosotomie is een andere dan die achter epilepsiechirurgie. Niet het weghalen van weefsel dat een aanval kan veroorzaken is het doel, maar het beperken van de spreiding van de aanval om zo verlies van bewustzijn te voorkomen (Mathews et al., 2008). Om hun benadering te onderbouwen voerden William Perrine van Wagenen, leerling van Harvey Cushing (1869-I939) en zijn assistent Robert Yorke Herren twee argumenten aan. Ten eerste: het bewustzijn gaat in de regel niet verloren bij aanvallen die qua omvang beperkt blijven tot één hemisfeer. Ten tweede: een aanval begint op één plek en verspreidt zich van daaruit over de hersenen. Vervolgens verwijzen zij naar vier klinische observaties die suggereren dat het mogelijk is de ontlading te beperken tot één hemisfeer. De eerste klinische observatie had betrekking op een analyse van de effecten van tumoren bij het cc. De conclusie van die analyse was dat als de vezels van het cc vernietigd waren door de tumor, de frequentie van de aanvallen daalde. De tweede observatie betrof een patiënt die geopereerd moest worden vanwege een traumatisch letsel. Bij de operatie werden op diverse plaatsen in beide hemisferen meningiomen gevonden. De ziektegeschiedenis van deze patiënt liet zien dat er aanvankelijk veel aanvallen waren maar dat de frequentie afnam na de operatie. Van Wagenen en Herren concludeerden dat dit te maken had met de aantasting van de associatiebanen. Een andere patiënt was bekend met een lange geschiedenis van frequente aanvallen. Na een cerebrovasculair accident stopten deze aanvallen. Toen de patiënt vijf jaar later overleed, bleek bij autopsie dat ongeveer tweederde van de vezels van het cc door de hersenbloeding waren vernietigd. Men veronderstelde dat de bloeding het epileptisch focus had vernietigd. Bij een vierde patiënt werd een soortgelijke geschiedenis beschreven: door een hersenbloeding in de rechterhemisfeer stopten de epileptische aanvallen. Met dit 'bewijs' in handen besloten Van Wagenen en Herren callosotomie uit te proberen bij patiënten met epilepsie. In de periode februari-mei I939 voerden zij deze ingreep bij tien patiënten uit. Bij enkele patiënten werd het cc gedeeltelijk doorgesneden, bij anderen werd een volledige callosotomie uitgevoerd. Bij enkele patiënten bleek na een eerste gedeeltelijke ingreep de epilepsie terug te keren en werd er een tweede (en eenmaal zelfs een derde) ingreep uitgevoerd (voor details zie Mathews et al., 2008). Er werd een uitgebreid neurologisch en psychologisch onderzoek voor en na de ingreep uitgevoerd. Het onderzoek naar de psychologische en persoonlijkheidsveranderingen werd uitgevoerd door Andrew Akelaitis (I904-I955) en in een reeks van tien artikelen beschreven. De algemene conclusie was dat de ingreep een positief effect had, ten eerste omdat de frequentie van de aanvallen afnam, ten tweede omdat er geen of nauwelijks negatieve neurologische of psychologische bijwerkingen waren.

\section{Kanttekeningen}

Van Wagenen en Herren geven een helder beeld van de tien patiënten met een korte beschrijving van hun epilepsiegeschiedenis, de aard van de chirurgische ingreep en de postoperatieve bevindingen. Bij geen van de patiënten werden echter 'harde gegevens' vermeld. Van Wagenen en Herren baseerden zich op vier klinische observaties, waarbij het driemaal om individuele gevallen gaat, terwijl de re- 
levantie van de hersenbloeding discutabel is. Ook verzuimden Van Wagenen en Herren te verwijzen naar een ingreep die Walter Dandy (I886-I946) reeds in I93I had uitgevoerd. Dandy verwijderde bij een jongen van viereneenhalf jaar een congenitale cyste in het cavum van het septum pellucidum, waarbij hij het cc doorsneed. Eén van de onvoorziene gevolgen was dat de epilepsie van de jongen verdween (Eling, 2005). Wat verder opvalt bij de onderbouwing van de ingreep is dat Van Wagenen en Herren niet ingaan op experimenteel onderzoek bij dieren naar de effecten van callosotomie. Voor een meer onderbouwde analyse van het intact blijven van psychologische functies verwijzen zij naar de psycholoog Akelaitis.

\section{Dierexperimenteel onderzoek}

Decennia voordat de ingrepen door Van Wagenen en Herren plaatsvonden werd er al dierexperimenteel onderzoek gedaan naar de effecten van callosotomie. In dit onderzoek was er vooral aandacht voor de overdracht van informatie van de ene hemisfeer naar de andere (transfer), zoals bijvoorbeeld na het leren van een geconditioneerde reactie. Alexander Von Koranyi (I89o) vatte de literatuur samen waarin hij studies vermeldde die in de ige eeuw werden gedaan. Hij besprak ook zijn eigen observaties. Dit dierexperimenteel onderzoek ging niet over epilepsie, maar liet wel zien dat als men de ingreep zorgvuldig uitvoerde, doorsnijding van het cc zelf geen negatieve effecten opleverde en dat negatieve effecten toe te schrijven waren aan beschadigingen aan de cortex tijdens de ingreep (Glickstein \& Berlucchi, 2008). Ook het werk van Konstatin Bykov (I885-1959) kan hier worden vermeld. Zijn studies over transfer van geconditioneerde reflexen bij honden met een doorgesneden cc toonden aan dat het cc wel degelijk nodig is voor interhemisferische communicatie en de transfer van informatie van de ene hemisfeer naar de andere. Bykov beschreef dit zo'n 30 jaar voor Roger Sperry (I9I3-I994) en Ronald Myers dat deden. De laatsten makten hiermee wel een nieuwe start met het onderzoek naar callosotomie bij epilepsie. Daaruit kwam een groot onderzoeksprogramma naar hemisfeerspecialisatie voort (Kane \& Finger, 1999).

\section{Bijwerkingen van callosotomie}

Akelaitis verzamelde de psychiatrische ziektegeschiedenis van de tien hierboven genoemde patiënten en hun pre- en postoperatieve IQ-scores (voor de details van deze patiënten zie Mathews et al., 2009). De callosotomie leek hierop geen effect te hebben gehad. Akelaitis onderzocht de lateralisatie van verschillende functies. De callosotomie leidde niet tot veranderingen in oog-, hand- of voetdominantie. Tot zijn grote verrassing vond hij ook geen effecten op complexe bimanuele activiteiten. Akelaitis verwachtte bij bestudering van de visuele waarneming dat hij bij perimetrisch onderzoek geen gezichtsvelduitval zou vinden. Hij verwachtte dat er asymmetrieën zouden optreden bij herkenning van objecten die in de verschillende halfvelden werden aangeboden, maar die halfveld-verschillen vond hij niet. Bij het onderzoek naar de taalfunctie bood hij visueel en tactiel aan één kant objecten aan die benoemd moesten worden. Een voorbijgaand probleem met schrijven en tactiel lezen (het herkennen van letters en woorden via tast) en tactiele objectherkenning werd bij slechts vier patiënten aangetoond. Ook in het onderzoek naar het vermogen een geluidsbron te lokaliseren, kennis van het lichaamsschema en de oriëntatie in de externe ruimte, het tijdsgevoel, ritme en gevoel voor muziek vond hij geen opmerkelijke effecten. Deze bevindingen onderschrijven de algemene conclusie van Van Wagenen en Herren: 'Als je een balk hebt, gebruik je die, als je er geen hebt, hoef je niet te treuren!' Deze conclusie komt overeen met de bevindingen bij patiënten bij wie per toeval een agenesis van het corpus callosum (het niet aangelegd zijn van het cc) werd vastgesteld. Ook hier werd geen relatie gevonden met psychologische klachten.

\section{Conclusie}

Een callosotomie zorgde er inderdaad voor dat het bewustzijn niet meer verloren ging, zoals Van Wagenen en Herren hadden verwacht. Maar het succes ging veel verder: de frequentie van de aanvallen nam sterk af! Hoe dat effect te verklaren is bespraken Van Wagenen en Herren helaas niet. Ondanks een discutabele onderbouwing hebben Van Wagenen en Herren aangetoond dat door een callosotomie bij epilepsie verspreiding van epileptische ontladingen vanuit één hemisfeer naar de tegenoverliggende hemisfeer kan worden tegengegaan.

\section{Referenties}

Eling, P (2005) Andrew Akelaitis over de gevolgen van callosotomie. Epilepsie, periodiek voor professionals, 3(1), 13-14. Glickstein M, Berlucchi G (2008) K.M. Bykov and transfer between the hemispheres. Brain Res Bull., 77(2-3):117-23. Kanne SM, Finger S (I999) Konstantin M. Bykov and the discovery of the role of the corpus callosum. J Hist Med Allied Sci. 54(4):572-90.

Mathews MS, Linskey ME, Binder DK (2008) William P. van Wagenen and the first corpus callosotomies for epilepsy. J Neurosurg. I08(3):608-I3.

Schijns OE, Hoogland G, Kubben PL, Koehler PJ (2015) The start and development of epilepsy surgery in Europe: a historical review. Neurosurg Rev. 2015 Jul;38(3):447-6I. Van Wagenen WP and Herren RY (I940) Surgical division of commissural pathways in the corpus callosum. Relation to spread of an epileptic attack. Archives of Neurology and Psychiatry, 44: 740-759.

Von Koranyi A (I89o) Über die Folge der Durchschneidung des Hirnbalkens. Archiv für Physiologie, 47: 35-42. 